・论坛・ 中国国家植物园专题

\title{
关于我国国家植物园体系建设的一点思考
}

陈进 $0^{*}$

中国科学院西双版纳热带植物园, 云南预腊 666303

陈进 (2022) 关于我国国家植物园体系建设的一点思考. 生物多样性, 30, 22016. doi: 10.17520/biods.2022016.

Chen J (2022) Some thoughts about China's national botanical garden system construction. Biodiversity Science, 30, 22016. doi: 10.17520/biods.2022016.

\section{Some thoughts about China's national botanical garden system construction} Jin Chen ${ }^{(1) *}$

Xishuangbanna Tropical Botanical Garden, Chinese Academy of Sciences, Mengla, Yunnan 666303

2021年10月12日，国家主席习近平在生物多样 性公约第十五次缔约方大会领导人峰会上发表主 旨讲话时指出: “本着统筹就地保护与迁地保护相 结合的原则, 启动北京、广州等国家植物园体系建 设”。2021年12月28日，国务院国函〔2021〕136号 文件正式批准建设北京国家植物园, 标志着我国国 家植物园体系建设进入实质性推进阶段。与此同时, 社会上对为何要建设国家植物园体系、如何建设国 家植物园及国家植物园体系出现不少讨论甚至争 论。现结合本人三十余年在植物园工作的实践, 对 我国国家植物园体系建设谈一点自己的思考。

\section{1 植物园的功能定位}

国内外学界和社会对植物园的功能定位一直 存在争议。多个专业的学术期刊如Trends in Plant Science (2009, Vol. 14)、《生物多样性》 (2017, 第9 期)、Plant Diversity (2017, Vol. 39)等, 都曾组织专题 文章就植物园的使命与功能展开讨论。造成人们对 植物园的功能定位认识产生分歧的原因是多方面 的。一方面, 从现代植物园 500 余年的发展来看, 在 不同的历史阶段, 植物园的中心工作和功能定位发 生了很多的变化(Heywood, 2017a; 黄宏文, 2018)。 早期的植物园多以收集药用植物为主, 或为大学教
学提供植物材料; 18、19世纪, 伴随欧洲殖民扩张, 植物园的主要功能是收集、保存从他国引种到欧洲 的各种植物, 并开展引种驯化和开发利用研究; 20 世纪上半叶, 植物园成为世界分类学与植物学相关 多个分支学科的研究中心; 直至 20 世纪 80 年代, 生 物多样性的概念被首次提出, 世界范围内植物园的 主要工作才逐步转移到植物多样性保护上来 (Heywood, 2017a; 许再富, 2017)。另一方面，植物 园本身具有多样性，因其规模、建园历史、资源以 及地理位置各不相同, 其工作重心亦可能存在诸多 差异。

洪德元院士在2016年上海辰山植物园学术委 员会年会上，以“三个“哪些””，提出他对植物园功 能定位的理解与思考(洪德元, 2016)。其中, “收集了 哪些? 拯救了哪些?”强调植物园之于植物多样性保 护的重要性, 也引发国内同行对植物园功能定位的 思考与讨论(详见生物多样性, 2017年第9期)。

以笔者之见，当今时代的植物园，特别是一些 大型、综合性的植物园, 其最基本最重要的功能即 是“植物多样性保护”。植物园的保护工作有别于其 他机构, 它能综合运用多种手段, 包括: 参与“就地 保护”的监测管理与研究(Chen et al, 2017), 对珍稀 濒危植物开展迁地保护、回归和野外种群重建(任海,

收稿日期: 2022-01-10; 接受日期: 2022-01-11

* 通讯作者 Author for correspondence. E-mail: cj@xtbg.org.cn 
2017), 为生态修复提供材料、技术支持, 以及开展 多层面、多形式的保护教育与环境教育等, 以实现 植物多样性保护的目标。

与此同时, 不同的植物园可以根据自身的特点, 重点在某一方面或某几方面发挥作用, 不应苛求千 篇一律。除了植物多样性保护以外, 植物园还具备 资源植物开发与可持续利用(贺善安和顾姻, 2017)、 城市生态建设(胡永红等, 2017)、植物文化的传播 (刘华杰, 2017)和国际交往等多种功能。

\section{2 植物园与植物迁地保护}

就地保护与迁地保护相结合的方式是开展生 物多样性保护的主要手段(Heywood, 2017b)。就地 保护即对野生生物的原生境开展保护, 它可以涵盖 保护地中的多个物种、生态过程和生态服务功能以 及生物的演化变异能力。迁地保护则可以有针对性 地对一些极度濒危的物种开展抢救性保护, 针对一 些现有保护区范围仍未能覆盖的受威胁物种, 以及 由于全球变化需要人工辅助迁移的物种开展重点 保护; 迁地保护还包括对濒危物种开展回归引种和 野外种群重建工作。同样重要的是, 将珍稀濒危物 种引种到植物园等场地开展繁殖、物候观察、抗逆 性和病虫害以及资源可持续开发利用研究, 将极大 地提高人们对这些物种的认知水平, 对它们的综合 保护亦至关重要。需要强调的是, 迁地保护并非是 在园区栽种一种植物, 也不需要对所有的野生植物 实行迁地保护。科学有效的迁地保护是在保护生物 学理论指导下, 开展有针对性的保护。

植物园是开展迁地保护的专业机构, 拥有植物 分类学、生态学、园艺学等方面的专门人才和相当 的土地, 可以重点针对所在地区气候带的受威胁植 物开展系统的迁地保护工作。

\section{3 国家植物园与国家植物园体系}

国家植物园代表了一个国家植物迁地保护的 最高水平, 承担履行生物多样性保护的国家任务和 职能; 针对所在地区主要气候带乃至世界范围内相 似气候条件下的植物开展系统的迁地保护与有针 对性的回归引种、野生种群恢复重建, 系统性地开 展生态文明与环境教育, 综合实力与国际影响力应 位居世界植物园(树木园)前列。国家植物园应该传
承植物园建设发展历史上积累的科学内涵、艺术外 貌和文化底蕴。

国家植物园体系是指由国家批准设立, 由若干 国家植物园和区域性综合植物园组成的、覆盖全国 主要气候带与生态系统类型的迁地保护研究网络 和生态文明教育基地，支撑国家的生态文明发展。

国家植物园体系建设是一个新鲜事物, 国际上 可以参照的案例并不多。一些发达国家如欧洲, 本 国的植物种类相对较少, 拯救本国植物免遭灭绝的 任务并不繁重。可供借鉴的案例如南非, 在全国不 同地区建立了包括 13 个植物园的国家植物园网络 体系, 统一受南非国立生物多样性研究所 (South African National Biodiversity Institute)领导, 执行统 一的标准, 有针对性地在全国开展植物迁地保护工 作; 同时与南非的保护地体系相互补充并形成有效 的合作机制。

中国是生物多样性大国, 本土植物种类 3.6 万 种以上，同时中国幅员辽阔，覆盖从热带到亚热 带、温带、寒温带等多个气候带。建立国家植物园 体系既是我国生态文明建设的一次创新性实践, 也 是中国这样一个生物多样性大国的必然要求。

国务院批准在北京建立首个国家植物园, 是综 合现有研究基础同时顺应北京作为首都的决策, 拟 建的北京国家植物园可满足在文化建设、服务首都 生态文明建设以及国际交往多方面的需求; 同时北 京国家植物园亦可针对京津冀、华北及部分东北地 区开展植物迁地保护工作。

诚然, 国家植物园体系建设是庞大、复杂的系 统工程, 需要加强组织领导与顶层设计, 需要坚持 标准、试点先行, 逐步推广与完善。

其一, 应把强化组织管理与支持地区发展统一 起来。我国现有的植物园分别隶属于科技、教育、 园林与城市建设、林业、医药等多个系统, 国家植 物园体系建设要强化组织管理, 需在坚持原有隶属 关系不变和“主建”的前提下, 强化国家林业和草原 局的行业管理作用; 因建设过程中需要大量资金, 提倡地方政府或所在城市给予一定的资金及政策 支持, 植物园发展的同时也可直接为所在地区的生 态旅游、生物产业发展和就地保护提供支撑。

其二, 应组建以国内外顶级保护生物学家、植 物园管理专家组成的科学委员会, 对国家植物园建 
设进行指导。科学委员会负责审议体系的顶层设 置、技术规程规范和质量评估, 以确保体系建设沿 着健康轨道发展。

其三, 坚持质量第一、试点先行, 树立标杆。 在现阶段, 全国植物园都应积极关注和参与北京、 广州两地的国家植物园试点建设。一些战略地位突 出、基础较好的植物园, 如西双版纳、上海、武汉 等, 也应积极争取各方面支持, 创造条件, 尽早纳 入国家植物园试点建设。同时, 积极推动在一些战 略性关键地区, 如青藏高原、广大西部腹地、热带 海岛等特殊生态区, 开展植物园或迁地保护设施的 筹划建设工作(许再富, 2017; 焦阳等, 2019)。

\section{4 变化的世界中植物园的新使命}

回望世界植物园发展五百多年的历史, 植物园 的工作重点及功能一直在调整。如今, 地球已经进 入“人类世”, 一方面, 地球生态系统无法回到原点; 另一方面, 人类必须通过科技进步和生产生活方式 的变革实现人与自然和谐发展。中国是世界上首个 把生态文明建设作为国家发展战略的国家。2021年 和2022年在昆明召开的生物多样性公约第十五次 缔约方大会, 将生物多样性主流化作为一个共同的 倡议提出, 并将制订有雄心和具有可操作性的 2020 年后生物多样性保护目标, 这些都将深刻影响全人 类的生物多样性保护工作。伴随中华民族的伟大复 兴和人类命运共同体的建设, 中国治理、中国方案 也将越来越多地影响着世界。

植物园事业迎来了从未有过的发展机遇, 同时 也呼唤创新的工作方案。中国植物园应积极探索在 变化的世界中更好地发挥自己的作用。一方面, 从 人类已经拥有的技术来看, 我们可以实现植物物种 的零灭绝(Chen \& Corlett, 2019); 另一方面, 世界范 围内植物受威胁仍然很严重。据最新的由 60 多个研 究机构 500 多位科研人员对全球 58,497 个树种的评 估, 有 $30 \%$ 的树种仍然处于受威胁状态, 有 142 种已 经在野外灭绝(BGCI，2021)。中国植物园未来应对 “新保护方式” (the new conservation)作积极探索, 构建全域的、更加整合的保护体系, 将就地保护、 迁地保护、近地保护、生态系统修复等多个手段综 合起来, 汇集所在地区各种保护力量, 包括国家公 园和保护区、地方政府、企业、民间组织和广大民
众，协调区域整体保护(Chen et al, 2017)。植物园应 该开展大量的专业性的保护教育和生态文明教育, 发起保护与教育相关的公民科学项目, 吸引广大民 众参与保护, 为实现全社会生产生活方式变革作出 重要贡献。植物园应加强植物对气候变化适应性的 系统研究, 通过遍布全国不同气候类型的植物园开 展联合研究, 为未来生态系统应对气候变化提供创 新方案。植物园同时应为支撑国家绿色“一带一路” 建设和人类命运共同体建设提供支撑, 在时机成熟 时，可以走出国门，帮助“一带一路”国家提高生物 多样性保护能力和环境教育事业(龙春林和马克平, 2017; 焦阳等, 2019)。国家植物园和国家植物园体 系建设无疑会对我国植物园担当新使命起到巨大 的促进作用。

\section{ORCID}

陈进 (D) https://orcid.org/0000-0002-9490-9981

\section{参考文献}

BGCI (2021) State of the World's Trees. BGCI, Richmond, UK.

Chen J, Corlett RT (2019) The Xishuangbanna Declaration on Plant Conservation. Biodiversity Science, 27, 114-115. (in Chinese and in English) [陈进, Corlett RT (2019) 西双版纳 宣言. 生物多样性, 27, 114-115.]

Chen J, Corlett RT, Cannon CH (2017) The role of botanic gardens in in situ conservation. In: Plant Conservation Science \& Practice (The Role of Botanic Gardens) (eds. Blackmore S, Oldfield S). Cambridge University Press, Cambridge.

He SA, Gu Y (2017) Plant exploration research and botanical garden vitality. Biodiversity Science, 25, 934-937. (in Chinese) [贺善安, 顾姻 (2017) 植物利用研究与植物园 的生命力. 生物多样性, 25, 934-937.]

Heywood VH (2017a) The future of plant conservation and the role of botanic gardens. Plant Diversity, 39, 309-313.

Heywood VH (2017b) Plant conservation in the Anthropocene-Challenges and future prospects. Plant Diversity, 39, 314-330.

Hong DY (2016) Three "What": Mission of a botanic garden. Biodiversity Science, 24, 728. (in Chinese) [洪德元 (2016) “三个哪些”: 植物园的使命. 生物多样性, 24, 728.]

$\mathrm{Hu}$ YH, Yang ST, Yang J, Vincent G, Chen XY (2017) Botanical gardens support urban sustainable development: A case study from the Shanghai Chenshan Botanical Garden. Biodiversity Science, 25, 951-958. (in Chinese with English abstract) [胡永红, 杨舒婷, 杨俊, 万吉尔, 陈晓亚 (2017) 植物园支持城市可持续发展的思考一以上海辰山植物 
园为例. 生物多样性, 25, 951-958.]

Huang HW (2018) "Science, art and responsibility": The scientific and social function changes of a 500-year history of botanical gardens. II. Intension of sciences. Biodiversity Science, 26, 304-314. (in Chinese with English abstract) [黄 宏文 (2018) “艺术的外貌、科学的内涵、使命的担当”

植物园500年来的科研与社会功能变迁 (二): 科学的内涵. 生物多样性, 26, 304-314.]

Jiao Y, Shao YY, Liao JP, Huang HW, Hu HB, Zhang QF, Ren H, Chen J (2019) Status and Future Strategies of Chinese Botanical Gardens. Bulletin of Chinese Academy of Sciences, 34, 1351-1358. (in Chinese with English abstract) [焦阳, 邵云云, 廖景平, 黄宏文, 胡华斌, 张全发, 任海, 陈进 (2019) 中国植物园现状及未来发展策略. 中国科 学院院刊, 34, 1351-1358.]

Liu HJ (2017) Promoting plant culture communication in a botanical garden from a natural history perspective. Biodiversity Science, 25, 938-944. (in Chinese with English abstract) [刘华杰 (2017) 从博物学视角推进植物园的植 物文化传播. 生物多样性, 25, 938-944.]

Long CL, Ma KP (2017) Challenges and opportunities for botanical gardens in a new era. Biodiversity Science, 25, 915-916. (in Chinese) [龙春林, 马克平 (2017) 新时期植 物园的机遇和挑战. 生物多样性, 25, 915-916.]

Ren H (2017) The role of botanical gardens in reintroduction of plants. Biodiversity Science, 25, 945-950. (in Chinese with English abstract) [任海 (2017) 植物园与植物回归. 生物 多样性, 25, 945-950.]

Xu ZF (2017) Botanical gardens' challenge - correspondence with Academician De-Yuan Hong's "Three 'What': Mission of a botanic garden”. Biodiversity Science, 25, 918-923. (in Chinese with English abstract) [许再富 (2017) 植物园的 挑战——对洪德元院士的“三个“哪些”: 植物园的使命”一 文的解读. 生物多样性, 25, 918-923.]

(责任编辑: 周玉荣) 